\title{
LA MUJER ROMANA Y EL EJERCICIO DEL PODER A TRAVÉS DEL CONTROL DE LAS FINANZAS: el CAso de Terencia, esposa de Cicerón
}

\author{
Coré Ferrer Alcantud \\ Universitat Jaume I
}

Resumen: Aparentemente, la vida de las aristócratas romanas durante la República se nos presenta sosegada y anodina en las fuentes. A pesar de que unas pocas fulguran dentro de una literatura más legendaria que realista, la mujer permanecía en el hogar, mientras que el hombre dominaba un vasto cosmos de posibilidades y sueños políticos extramuros. No obstante, en los últimos coleos del régimen republicano una mujer vuelve a brillar entre las demás matronae: Terencia, la primera esposa de Cicerón. Y lo hace interviniendo en las finanzas, un espacio concerniente a los varones. Gracias a la obra epistolar de Cicerón, una de las mayores fuentes de la época, observaremos cómo Terencia habrá de gestionar el patrimonio familiar durante las ausencias de su marido, constituyendo así una acción sin precedentes.

Palabras clave: Terencia, mujer aristócrata romana, finanzas femeninas, Cicerón, República romana.

ABSTRACT: According to the sources, the life of the upper class Roman women was both quiet and insignificant during the Republic. In spite of the fact that a few ones stand out within a more mythical rather than realistic ancient literature, women had to stay at home, whereas men, outside «feminine» place, had the choice to access an enormous universe of possibilities and political dreams. Nevertheless, one woman will shine above the other matronae in the last decades of the Roman Republic: Terentia, Cicero's first wife. Thanks to this eloquent orator -the most important source of those last times- and his epistolary work, we will be able to observe how this woman could manage the family finances during the absences of her husband; we will see that this was an action which followed no patterns. 
Keywords: Terentia, upper class Roman woman, feminine finances, Cicero, Roman Republic.

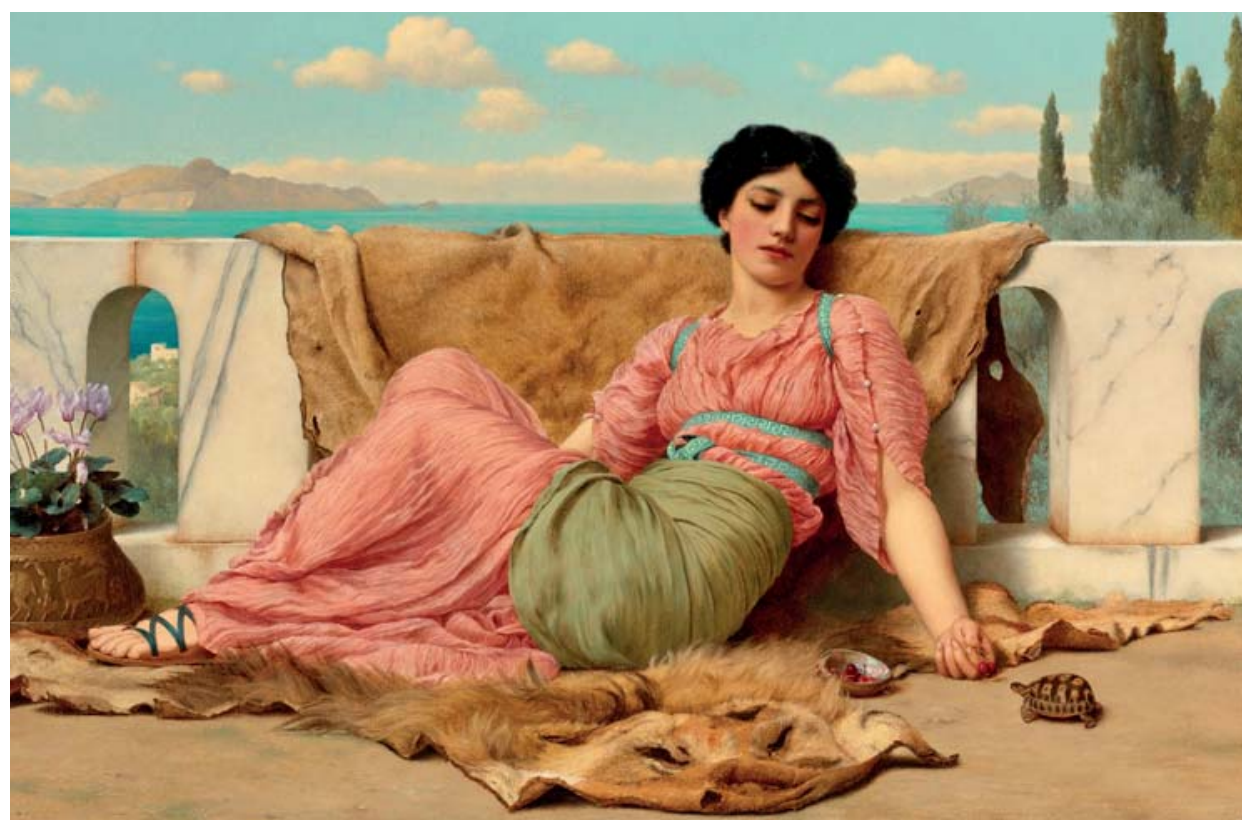

La ociosa pose de esta joven matrona romana, retratada por John William Godward - uno de los artistas más significativos del movimiento prerrafaelista-, es un distorsionado ideal neoclásico, poco acorde con la realidad de Terencia (J. W. Godward, 1906)

El público cree que la gracia, el ingenio y el desenfado están en la escena. Y no es cierto. La función interesante, viva y a cada instante renovada, está aquí abajo, entre las últimas butacas.

Luz de candilejas: el teatro y sus miserias

Daniel de la Vega (1930)

\section{INTRODUCCIÓN}

\section{Matrona}

Con el término matrona se conoce a la perfecta mujer romana. Es disciplinada, esposa fiel, madre sensible e imparcial, persona culta y educada, alguien incorruptible, de natural hermosura, que ostenta gran entereza ante la adversidad, apacible, decorosa, pía, delicada... Es decir, una persona absurdamente mitológica. 
En efecto, estas son las características femeninas que encontramos al tratar algunas fuentes literarias antiguas referentes a la mujer republicana. ${ }^{1}$ Con el cambio de régimen se desarrolla un estilo literario orientado a la propaganda del princeps y la de toda su familia que no solo afecta a la política ortodoxa, sino también al resto de elementos sociales que participan en la vida de Roma. Evidentemente, las mujeres también son un componente de esta propaganda política, convirtiéndose algunas de ellas en protagonistas de este tipo de discurso. Algunos autores a las órdenes del emperador, como es el caso de Tito Livio, crearon estos modelos femeninos con el fin de «reeducar» a las mujeres de su tiempo. Las «excesivas» concesiones legales que en los últimos años de la República venían favoreciendo a las mujeres, se estaban volviendo en contra de Roma. ${ }^{2}$

Por otro lado, la mayoría de ellas son o bien personajes puramente legendarios o bien figuras tan remotas, que no podemos sino rebatir algunos de aquellos adjetivos con los que abría este ensayo. Por tanto, antes de empezar a comprender cómo actuaba realmente la mujer durante los últimos años de la República, el historiador se enfrenta a un doble problema: el primero, es la imponente falta de información y, en segundo lugar, el daño que provoca la fantasía o manipulación de estos autores que escribieron sobre mujeres legendarias en unos años en los que la población intentaba adaptarse a cambios tremendos.

\section{La mujer a comienzos de la República}

Resulta evidente que las victorias en las guerras de expansión reportaron no únicamente un notorio crecimiento económico, sino también nuevas maneras de pensar que forjaron un gran desarrollo de la intelectualidad. ${ }^{3}$ En pocas palabras, a partir del siglo iII a. C., la República evoluciona al mismo tiempo que lo hace la sociedad romana y, por ende, también la mujer.

La mujer de comienzos de la República aparece en las fuentes como el centro de la unidad familiar. Esta matrona, cuyo destino no era otro que casarse para engendrar hijos -futuros ciudadanos romanos-, gozaba de ma-

1. Susan Treggiari, Terentia, Tullia and Publilia: the Women of Cicero's Family, 2007, Abingdon, p. 16: modestia, verecundia y comitas son las bondades femeninas, mientras que su equivalente masculino sería la virtus.

2. Dentro del programa político de Augusto se buscaba el aumento demográfico, cuyo índice, debido a los enfrentamientos al final de la República, se hallaba macilento. En este sentido, el ius trium liberorum, que data del 9 a. C., fue promulgado por Augusto en su reforma legislativa como respuesta al mentado descenso: las mujeres quedaban libres para disponer por entero de su patrimonio si concebían tres hijos como mínimo (Suzanne Dixon, Family finances: «Terentia and Tulia», en Rawson, B. (ed.), The Family in ancient Rome: new perspectives, Londres, 1986, p. 117, n. 23: tres hijos en el caso de las ingenuae y cuatro para las libertae, según la lex Iulia del 18 a. C. y la lex Papia Poppaea del 9 d. C. -incluyendo a las vestales; Richard Bauman, Women in Politics in Ancient Rome, Londres, 1994, p. 58-. Eva Cantarella, La calamidad ambigua, 1991, p. 211 (en adelante, Eva CANTARElla, 1991a).

3. Pierre Grimal, Le siècle des Scipions. Rome et l'Hellénisme au temps des Guerres Puniques, París, 1953 
yor independencia en comparación con mujeres pertenecientes a otras sociedades antiguas. Es cierto que ostentaba novedosas libertades, aunque en ocasiones esta libertad resultaba casi imperceptible, pues cumpliendo con su rol de esposa y madre su obligación legal e inmediata era hacerse cargo de todo lo que sucedía en la casa. De este modo, mientras que el ejercicio de las magistraturas, la acción política o la participación militar eran tareas desempeñadas por el varón en el espacio público, la esfera «privada» de la vida en Roma se corresponde con el único lugar legítimamente femenino: el hogar. El papel de la mujer en la casa es de gran importancia. Ello queda plasmado en numerosos procedimientos que la vinculan al espacio doméstico con el fin de reforzar las funciones a las que ideológica y socialmente estaban sometidas en el periodo republicano, materializándose en los característicos ritos de paso, propios de la religión romana. Sin embargo, la mujer romana también dirigía la educación de sus hijos y con tal fin, al menos durante la infancia, niños y niñas indistintamente compartían las mismas enseñanzas bajo el techo de la domus. ${ }^{4}$

En cuanto al matrimonio, este ha de ser entendido como un mecanismo de carácter plenamente contractual. Bajo estas condiciones, la mujer ocupaba una posición secundaria, siendo utilizada como herramienta en transacciones políticas con dos propósitos elementales -además de engendrar hijos-, que son: por un lado, engrosar el patrimonio de su futuro marido y, por otro, aumentar el estatus social de los hombres en la nueva familia a través de la promoción política. El reconocimiento social del varón en Roma, por tanto, dependía en mucho de la categoría económica de la mujer escogida, ya que tanto el esposo como los hijos -fruto de esta negociada unión política que es el matrimonio-, necesitan del patrimonio de la esposa, o de la madre, para cumplir con los propósitos de la vida pública: acceso al censo, vestimenta, armamento, ofrendas, rituales religiosos, actos políticos o ceremonias funerarias. Por otro lado, las finanzas originadas dentro y para la casa también eran competencia de la esposa, no obstante, esta gestión debía ser supervisada por el esposo o un tutor. En este sentido, la mujer, que nace y vive para el matrimonio, y a pesar de estar supeditada a un cuerpo de leyes de dominio masculino, contribuye a la economía de su nueva familia con la aportación de la dote, patrimonio que le corresponde por derecho, pero que habrá de gestionar su esposo en adelante. ${ }^{5}$

4. Emily A. Hemelrijk, Matrona docta. Educated women in the Roman élite from Cornelia to Julia Domna, 1999, pp. 64-71, sobre el rol de las matronae con respecto a la educación otorgada por estas a sus hijos, partiendo el ejemplo de Cornelia, madre de los Graco.

5. Livio, 34, 2, pone en boca de Catón el Censor estas palabras: «nuestros antepasados no quisieron que mujer alguna participara en asuntos, incluso privados, excepto a través de un tutor, colocándolas bajo la tutela de sus padres, hermanos o esposos»; según Livio, son pronunciadas a favor del mantenimiento de la lex Oppia en el 195 a. C. -ley en contra de la ostentación femenina activa desde el 215 a. C.- para que no sea abrogada. Por ende, la tutela supeditaba cualquier acción de la mujer a las decisiones del paterfamilias o un tutor y, precisamente, las limitaciones más importantes eran las orientadas a contener el patrimonio familiar. Para más información sobre esta ley y sus consecuencias véase CLAUDINE HERRMAN, Le rôle judiciaire et politique des femmes sous la République romaine, Collection Latomus, Bruselas, 1964, pp. 64 y ss. 
La dos o dote era el patrimonio exclusivo de la mujer. Sin embargo, al estar supeditado a la gestión del esposo o tutor, podía ser requerido para el auxilio del Estado, especialmente en tiempos políticamente comprometidos -situaciones que se repiten de forma cíclica: por ejemplo, hay crisis tras las guerras anibálicas o las posteriores guerras civiles-, provocando en uno y otro momento que la mujer tenga que desplazar su radio de acción desde la «simplicidad» que requiere la atención del hogar hacia el absoluto sostén en términos económicos de la casa y la familia. Asimismo, la legalidad femenina se fue abriendo tímidamente a modo de compensación por participar en la recuperación de Roma: el primer ejemplo lo encontramos el 295 a. C., cuando el Senado concedió a las matronas el honor de acudir en carro a festividades y ceremonias religiosas, pudiendo utilizarlos también los días ordinarios. ${ }^{6}$

\section{La mujer a finales de la República}

Del mismo modo que para conocer detalladamente los últimos momentos de la República romana es habitual acudir a la obra de uno de los actores principales de aquellos tiempos, el prolífico Cicerón -coprotagonista, además, de este estudio-, resulta indispensable, en aras de la verdad, atender también a la información jurídica desprendida de los tratados de Gayo, Aulio Gelio y Ulpiano, con tal de mostrar las limitaciones de las mujeres pertenecientes a la aristocracia dentro de la sociedad romana. Asimismo, parece acertado combinar estos dos medios de estudio con la técnica analítica desprendida de la sociología, a fin de encontrar un cómodo equilibrio entre la parte más subjetiva -la obra epistolar de Cicerón-, y la más objetiva -la legalidad romana-.

En este sentido, cabe sintetizar que las limitaciones femeninas en Roma eran principalmente tres: no tienen permitido prestar servicio militar, no pueden votar y no pueden desempeñar una magistratura. ${ }^{7}$ Queda claro, por tanto, que al no tener permitido participar en la vida pública romana, el único cometido de la mujer era dedicarse por entero a la familia, tanto a engrosarla biológicamente como afanarse en atender las necesidades de todos sus miembros. A ojos de un observador actual, esta vida condicionada y restringida podría resultar sorprendente, por lo que merece la pena recordar el carácter contractual del matrimonio, cuyo acuerdo definitivo resultaba de una «compra»: la compra de una esposa.

6. Es el primer ejemplo de colaboración económica femenina (Livio, 5, 25): el 295 a. C. Roma no pudo completar el pago de la décima parte del oro del botín que había prometido Camilo para el templo de Apolo en Delfos; no habiendo oro suficiente, las matronae hubieron de aportar sus joyas al tesoro público para que el Senado comprara oro, por lo que fueron recompensadas de este modo. También VAlERIO Máximo, $5,6,8$.

7. Digisto, 50, 17, 2 (Ulpiano, I, ad Sabinum). Por tanto, la mujer no tiene cabida en el marco legal público para ejercer el ius suffragii, es decir, no puede votar en los comicios y en el senado; no puede, asimismo, ostentar cargos públicos y desempeñar magistraturas, es decir, el ius honorum; ni, tampoco, practicar el ius militiae para formar parte del ejército. 
Aun así, la mujer queda amparada por la legalidad en varios aspectos, sobre todo a finales de la República. Aspectos que podríamos resolver en cuatro: la dote, el divorcio, la tutela y, por último, la herencia. En primer lugar, el paterfamilias de la mujer tenía que hacerse cargo previamente de futuras expensas cuando la entregaba en matrimonio a otro hombre: la dos es un conjunto de bienes patrimoniales que, a modo de agasajo, pretende cumplir dicha función. Asimismo, es el esposo el encargado de gestionar estos bienes, pero en ningún caso le pertenecen, ya que legalmente la dote ha de ser entendida como el patrimonio propio de la esposa, ${ }^{8}$ es decir, que le corresponde únicamente a ella y, en consecuencia, a su antigua familia. Por tanto, a pesar de estar sujeta a ciertas retenciones derivadas del matrimonio, la dote, había de ser restituida en su totalidad en el caso del fallecimiento del cónyuge varón o bien por disolución del matrimonio. ${ }^{9}$

En segundo lugar, el divorcio. Ciertamente, no solo existió, sino que se daba con asombrosa frecuencia. ${ }^{10}$ De un modo evolutivo, el carácter contractual que en origen tenía el matrimonio se transformará con el fin de establecer convenientes uniones clientelares con precisos objetivos políticos: el mayor ejemplo de la utilización del matrimonio como elemento de promoción política a finales de la República tal vez sea el de las diversas uniones de Julio César, todas ellas estratégicamente interesadas, ${ }^{11}$ incluido el matrimonio de su hija con Pompeyo para sellar la gran alianza entre ambos líderes. Consecuentemente, la disolución del matrimonio significaba el final de las relaciones establecidas entre dos familias políticamente unidas mediante lazos clientelares y auxiliadas económicamente. Por tanto, el aumento de poder adquisitivo y social que proporcionaba la mujer a su nueva familia era alcanzado a través de la dos.

Asimismo y desde tiempos remotos, ${ }^{12}$ la mujer es equiparada a sus hermanos en la herencia patrimonial. Para esta, heredar suponía una ventaja sobre los varones solteros de su familia original, puesto que ella no solo se beneficiaba

8. Marta Morineau Iduarte, Diccionario de Derecho Romano, 2006, v. «dote», p. 49.

9. La retentio propter era el mecanismo según el cual el marido podía retener o sustraer cierta cantidad de la dote original y no devolverla en su totalidad una vez efectuado el divorcio. Había variación según el motivo que impulsaba su uso, bien en relación a los gastos derivados del matrimonio, bien por los bienes donados del marido a la esposa, bien en consideración a los hijos o también realizando deducciones sobre bienes como indemnización por cargas contraídas del esposo a favor de la mujer.

10. La mujer tenía la capacidad de divorciarse de su esposo. A pesar de llamar nuestra atención, esta no fue una «concesión» propiamente romana, sino que también fue llevada a cabo en Grecia -a pesar de que las atenienses gozaban de menor cobertura jurídica que las romanas-. Recordemos el relato de Plutarco $(A l c ., 8,3)$ sobre el estratega del siglo v a. C. Alcibíades y su esposa, Hipareta, quien, ofendida por aquel, decidió presentar una demanda de divorcio personalmente, ya esta poseía la capacidad para hacerlo sin intermediarios. Actuó conforme a las leyes, sin embargo, la reacción del esposo fue exagerada: este la asió del brazo y la llevó a casa arrastrándola por el ágora.

11. Sarah B. Pomeroy, Diosas, rameras, esposas y esclavas. Mujeres en la Antigüedad clásica, Madrid, 1999, p. 178.

12. En la recopilación de materiales que componen la tabula $V$ de la Ley de las XII Tablas (FIRA), se desprende que, al no haber distinción entre hombres y mujeres, se entiende que la capacidad de heredar era equivalente entre ambos sexos. 
de lo que le correspondería en la partición testamentaria, sino que, además, disfrutaba de la dote al contraer nupcias. ${ }^{13}$ La mujer, por tanto, gozaba de dos fuentes de ingresos en detrimento de sus hermanos varones solteros, los cuales solo disponían de la herencia como única vía de inyección financiera. ${ }^{14}$ Para detener esta anomalía se aprobó en el 169 a. C. la lex Voconia, según la cual quedaba prohibido que heredasen las mujeres pertenecientes al primer censo, es decir, las más ricas de Roma. Además del conocimiento pasivo del Senado que nunca actuó en contra de esta ley, las mujeres encontraron la manera de esquivarla por medio de escurridizos laberintos legales. ${ }^{15}$

Por último, la jurisprudencia matrimonial es modificada y el matrimonio cum manu, una unión subyugante, predominantemente de permuta o compra de la futura esposa, ${ }^{16}$ con el paso del tiempo llegará a ser una asociación sine manu, es decir, un convenio entre dos familias en el que la mujer goza de mayor libertad. ${ }^{17} \mathrm{Al}$ mismo tiempo que va constituyéndose el sistema matrimonial «sin mano»-que se puede comparar, con muchísimo cuidado, con una suerte de «separación de bienes», ${ }^{18}$ según las leyes españolas-, también se relaja la tutela de la mujer. Ello significa que, al final de la República, el papel que desempeñaba el paterfamilias o el tutor que le sustituye si este falta, se irá relajando debido a que la mujer puede «comprar» un tutor para que haga de mediador de sus propias gestiones y otros trámites. ${ }^{19}$

13. Según advierte Eva Cantarella, La mujer romana, Santiago de Compostela, 1991, p. 36, este fue un inconveniente que los atenienses supieron evitar excluyendo a la mujer de toda herencia (en adelante Cantarella, 1991b).

14. Guillermo SuÁrez Blázquez, La dote de la mujer romana en el derecho de sucesiones, Orense, 1997, p. 25, observa acertadamente que «en la colación de la dote hay un anticipo patrimonial en vida del padre a la hija ad sustinera onera matrimonii, que es el que genera ventajas en los derechos sucesorios de aquella».

15. Ab intestatio y fideicomissum en MORINEAU, DDR, v. «sucesión legítima en el derecho antiguo»; p. 144; v. «fideicomiso», p. 60. Cicerón critica la lex Voconia considerándola injusta para las mujeres (de rep., 3,17$)$.

16. Eva Cantarella, Pasado próximo. Mujeres romanas de Tácita a Sulpicia, Madrid, 1996, pp. 107 y ss.

17. Eva Cantarella, $1991 a$, p. 201, resuelve adecuadamente que la mujer «en la época más antigua (...) pasaba de la familia originaria a la del marido, donde se encontraba sometida a un poder familiar (manus), no muy diferente en extensión y contenidos de la patria potestas», de una mano a otra. Aunque escéptica, nos dice también Eva Cantarella (1991b, p. 43), que en el siglo il a. C. cae en desuso a favor de la unión sine manu, «matrimonio consensual» que ofrece cierta desvinculación entre la mujer y su nueva familia, otorgándole mayor libertad. A este respecto merece la pena señalar, en relación a la herencia, la clara desventaja en la que se encuentran los demás miembros de la familia, ya que la mujer casada cum manu podía beneficiarse económicamente en tres situaciones: la recepción de la dote, la herencia en caso de fallecer el paterfamilias de su familia original, y la herencia del paterfamilias de la familia actual. Quizás esta sea una forma más adecuada de explicar el cambio de cum a sine manu.

18. Jane F. GARdner, Women in Roman Law and Society, Bloomginton, 1991, pp. 74-75, sobre la transformación de los bienes «compartidos» en bienes «separados»; hasta su prohibición de la mano de Augusto, las mujeres podían - gracias a la dote- auxiliar a sus esposos económicamente, bien a través de regalos, bien ayudándoles con las deudas directamente. Ulpiano, Dig., 16, 1, 2.

19. Veáse nota 3 arriba; Jane F. Gardner, 1991, p. 19. Sobre la discusión acerca del tutor legitimus, veáse John K. Evans, War, women and children in Ancient Rome, Londres, 1991, pp. 8-9. 
Evidentemente, estas concesiones a las mujeres solo tienen un objetivo: utilizar el patrimonio femenino para recuperar la bonanza financiera del Estado. Es así como ciertas mujeres, pertenecientes a la élite romana, haciendo uso tanto de su dote como de sus influencias políticas familiares, son vistas en las fuentes como protagonistas en la economía y las finanzas del periodo republicano. Este es, precisamente, el caso de Terencia, primera esposa de Cicerón, el cual nos informa sobre su poder económico y su influencia política en las cartas que escribió durante sus ausencias. ${ }^{20}$

\section{LA IMAGEN DE TERENCIA}

El temor que ocasionaba este «licencioso dominio de la economía» de manos de una mujer -siempre entendido desde la óptica de un varón republicano romano, como fue Cicerón-, provocó no solo el divorcio entre ellos, sino la mala fama de Terencia, conservada hasta hoy. ${ }^{21}$ Esto es precisamente lo que pretendo desmontar mediante una atrevida propuesta: tras el análisis tanto de las cartas como de los últimos estudios al respecto, propongo, en primer lugar, que el manejo de las finanzas podría ser práctica habitual de las mujeres que gozaban del mismo estatus social que Terencia. En segundo lugar y en esta línea de cotidianeidad, proyecto la duda sobre quién de los dos programó el divorcio, Cicerón -como viene dándose por sentado- o bien fue su esposa la que tomó esta decisión, amparada en el avance jurídico de la mujer en periodo tardorrepublicano.

Como viene siendo habitual en los estudios de la Antigüedad, el problema se encuentra en las fuentes. La ausencia de información sobre la que fue primera esposa de Cicerón dificulta el trabajo y nos obliga, en muchos momentos, a contrastar y presuponer comportamientos sociales. ${ }^{22}$ Obviamente, la obra epistolar de Cicerón es lo único que nos acerca directamente a una reconstrucción de lo que pudo haber pasado. Sin embargo, no debemos olvidar que las cartas reflejan un punto de vista subjetivo, una visión protagonizada por un varón, cuya conocida astucia no desdeña la posible publicación de esta correspondencia, así como la difusión y conocimiento de su contenido:

20. Las cartas que nos interesan para este estudio son las dirigidas a su amigo de juventud, Tito Pomponio Ático, y a su primera mujer, Terencia; todas ellas ocupan un espacio cronológico comprendido entre el año 68 y el 44 a. C., un año antes de la muerte de Cicerón.

21. Del esmerado artículo de Suzanne Dixon (1986) se desprende la influencia de la negativa visión que Plutarco tenía sobre Terencia (Cic., 20; 29; 30; 41). Susan Treggiari, Terentia, Tullia and Publilia, the Women of Cicero's family, Londres, 2007, pp. 155 y ss. -autora del segundo trabajo más importante sobre la mujer de Cicerón-, recoge la tendencia hostil que manifestaron importantes investigadores hacia Terencia en los últimos años.

22. Susan Treggiari, Roman Social History, Londres, 2002, p. 54, explica cuáles son los obstáculos que encontramos al investigar a su hija Tulia, por lo que nos sirve para hacernos una idea de las dificultades en el caso de Terencia en particular. 
No hay ninguna «recopilación» de mis cartas, pero Tirón [liberto de Cicerón] tiene alrededor de setenta y cabe tomar algunas de las que tienes tú. Conviene que yo las repase y las corrija. Entonces por fin se podrán publicar. ${ }^{23}$

Por otro lado, no conservamos ninguna carta de su esposa, lo cual supone un gran obstáculo. ${ }^{24}$ Sujetos a este escenario, es así como comienza el ejercicio reconstructivo: ¿quién fue Terencia? Gracias a la reciente biografía elaborada por Susan Treggiari (2007), y aunque lo cierto es que nada sabemos con certeza acerca de esta mujer y ni siquiera deberíamos confiar irrebatiblemente en las cartas conservadas de su esposo, conocemos algunos datos más que facilitan la construcción de posteriores conclusiones.

A pesar de que la fecha del matrimonio y la edad que tenía cuando se casó nos son desconocidas, ${ }^{25}$ sí sabemos que Terencia contrajo nupcias con Cicerón con quien mantuvo un largo matrimonio que duró alrededor de treinta años. Terencia tuvo dos hijos: Tulia, nacida en el 79 a. C., poco después de que su matrimonio comenzara, ${ }^{26}$ y Marco, nacido en el 65 a. C. Además de su esposo e hijos, su único pariente conocido fue una hermanastra llamada Fabia que formaba parte del grupo de las vírgenes vestales (Salustio, Cat., 15, 1). Se sabe, por la gran dote de 120.000 dracmas que aportó, ${ }^{27}$ que provenía de una familia adinerada y que gozaba de un gran estatus social, del que se habría beneficiado Cicerón al casarse con ella. Es posible que su padre, fallecido - por lo que su madre se volvió a casar con un tal Fabio, padre de su hermanastra vestal-, dejara todos sus bienes en herencia a Terencia como su única hija. ${ }^{28}$ A pesar de que no sabemos qué fue de ella desde la muerte de Cicerón y el final de la correspondencia, parece que pudo haber vivido hasta los 103 años (Plinio, $H$. N., 7; Valerio Máximo, 8, 13, 6).

De su matrimonio con Cicerón merece la pena destacar que compartieron buenos momentos, especialmente gratos cuando Cicerón alcanzó el consulado en el año 63 a. C. Según las leyes romanas, la esposa dona su dote al matrimonio para contribuir con los gastos que este conlleva y, en consecuencia, ayuda al varón a promocionarse políticamente gracias al incremento de la economía familiar. A cambio, este debe asegurar que la posición social de su esposa

23. Cicerón, ad Att., 410, 5 (aquí y en adelante utilizaré la traducción de Rodríguez-PAntojA, Gredos, 1996). Asimismo, damos por sentado que también Terencia colaboró en la recopilación de dicha correspondencia, ya que conservamos gran cantidad de las que su esposo le envió.

24. Emily A. Hemelrijk, pp. 203-206.

25. JANE F. GARDNER, pp. 38-41, sobre la edad legal en la que una joven podía contraer matrimonio. No obstante, lo hace basándose en la aportación legislativa de Augusto, el primero en establecer los 12 años como edad mínima.

26. Susan Treggiari, 2007, p. 32. sugiere que se celebró en el 80 o 79 a. C., un matrimonio que concertaría la enorme fortuna de Terencia con la que prometía ser una próspera vida política de Cicerón.

27. Plutarco, Cic., 8. A propósito del resto de bienes que aportó en la dote, veáse Teresa Carp, «Two matrons of the Late Republic», en Foley, H. P. (ed.), Reflections of Women in Antiquity, Nueva York, 1989, pp. 347-348: dos bloques de insulae, tierras y una villa de gran productividad que consideró vender durante el exilio de su marido, en el 58 a. C.

28. Según Plutarco, 90.000 dracmas, Cic., 8. 
aumente, acompañando a la que corresponde al cargo político del cónyuge; Terencia logró afianzar así su lugar en la aristocracia romana. No obstante, fuentes posteriores a Cicerón censuran su comportamiento «intrusivo», mencionando la influencia que ejercía sobre su marido, participando indirectamente en las acciones políticas que emprendería su esposo en el futuro. ${ }^{29}$

A pesar de su infame recuerdo, lo que sugieren tanto la obra epistolar de Cicerón como los presentes investigadores es que, además de adinerada, Terencia fue una mujer devota en el ámbito religioso -basándose en el relato de Plutarco una vez más,$-^{30}$ conservadora en términos políticos y gran gestora en asuntos financieros. En este sentido y a pesar de pertenecer a la nobleza y contraer nupcias con uno de los personajes más ilustres del momento, hubo de lidiar con la adversidad en numerosas ocasiones llegando a compaginar la gestión de la economía del hogar, bajo la tímida supervisión de su liberto Filótimo, ${ }^{31}$ con el manejo de las finanzas de su esposo ayudándose del amigo de la familia, Ático. Los gastos ocasionados en la domus eran tarea de la mujer. No obstante, pudo actuar como una auténtica materfamilias mientras Cicerón se encontraba fuera de Roma y ello solo puede deberse a dos circunstancias. La primera de ellas obedecería a que la compleja situación en la que se encontraba su familia, debido al exilio y posteriores ausencias de su esposo, la empujó a encargarse de los asuntos financieros de este, tales como el cobro de rentas, administración de propiedades e incluso su venta en momentos de gran apuro. La segunda actitud pudo venir dada por el hecho de que administrar las finanzas fuese una práctica habitual entre las mujeres de su rango social, como demuestra el hecho de que esta tarea no aparezca criticada en las cartas que intercambiaron Cicerón y Ático. Como vemos, son dos respuestas totalmente opuestas e incompatibles a una misma pregunta, no obstante, ambas son válidas debido a la falta de información sólida. En cualquier caso, queda patente que Terencia sobrepasaba las expectativas que se tenían de la mujer republicana. ${ }^{32}$

Las continuas desavenencias entre Cicerón y el que fue tribuno de la plebe Publio Clodio Pulcro, provocaron el exilio del arpinate en el 58 a. C. bajo la acusación de haber asesinado a ciudadanos romanos durante la conspiración

29. Según Plutarco, Cic., 20, Terencia era una mujer ambiciosa que prefería tomar parte en los avatares políticos de Cicerón, en lugar de ocuparse de forma adecuada de las finanzas que requerían su administración.

30. Por el contrario, SARAh B. Pomeroy, 1999, p. 229, sugiere que la religión en la mujer podía suponer una dedicación real, pero advierte que podría atender también a una obligación social.

31. Teresa Carp, p. 354, n. 21, se sirve del trabajo de J. A. СrooK, «Women in Roman succession», en Rawson, B. (ed.), The Family in ancient Rome: new perspectives, Londres, 1986, p. 115, n. 12, para mencionar que la supervisión de este liberto no respondía a una tutela restrictiva en cuanto a la gestión financiera de Terencia -como debería haber sido, según la jurisprudencia romana-, interpretando que esta mujer gozaba de libertad administrativa con respecto al tutor.

32. Un ejemplo de esta excepcional actitud se encuentra en ad Att., 35, 4, donde Cicerón agradece la mediación de Ático entre su esposa y un tal Mulvio, un recaudador que fue en busca de Terencia para reclamarle pagos por ocupar ager publicus - práctica habitual entre los más acaudalados-, a lo cual aquella se negó. Veáse también Teresa CARP, p. 348. 
de Catilina sin el consentimiento último del Senado, acusación que había de acatarse con la pena capital y la confiscación de sus bienes: ${ }^{33}$ "Mis enemigos me han quitado todos mis bienes, pero no mi personalidad $\gg .^{34}$

No obstante, casados por el procedimiento sine manu, el patrimonio de Terencia no tenía por qué ser expropiado. Con todo, ya que es el hombre quien dispone del patrimonio de la mujer, su dinero hubo de ser utilizado para la educación y subsistencia de sus hijos, el mantenimiento del hogar y el servicio, las cargas ocasionadas en la casa, encargándose, además, de los dispendios propios de la posición social y el pago de deudas, incluidas las que Cicerón ya no podía financiar. Por tanto, Terencia hubo de ocuparse de toda la economía, no solo de la que le correspondía según la legislación romana, atendiendo a los consejos de su liberto Filótimo y de su amigo Ático: «Tú [Ático] atiende a todo lo que pasa ahí y dirígelo. Terencia te da muchísimas gracias». ${ }^{35}$

Aun así, con sus reformas legales, Clodio consiguió imponer multas a todos aquellos que apoyaran la causa del exiliado, por lo que las propiedades de Terencia también se verían afectadas finalmente. ${ }^{36}$ Hubo incautación patrimonial, incendios de ciertas propiedades, expropiación de tierras pertenecientes a los bienes matrimoniales, e incluso humillación pública para nuestra protagonista, quien hubo de refugiarse en una ocasión en el templo dedicado a Vesta, quizás protegida por su hermanastra y sus compañeras, siendo después sacada del templo y arrastrada ante los tribunos. En la misma carta de donde extraemos esta información, leemos:

Sufro porque tú, pobre y expoliada, te ves obligada a afrontar una parte de los gastos. Si esta empresa llega a su término, todo irá bien. Pero si este infortunio continúa persiguiéndonos, ¿sacrificarás, pobre mujer, el resto de tus bienes? Te lo suplico, vida mía: en lo que atañe a los gastos, deja que otros, que tienen disponibilidad, hagan frente si en estos momentos tienen voluntad. ${ }^{37}$

Contrariamente a obedecer órdenes de los varones que la rodeaban, en las cartas se vislumbra que Terencia dejó a un lado el típico patrón de comportamiento femenino y se encargó no solo de dirigir las finanzas de su

33. Francisco Javier López Barja y Pedro Lomas Salmonte, Historia de Roma, Madrid, 2004 p. 212.

34. Así le habla Cicerón a su amigo camino del exilio (ad Att., 50), en abril del 58 a. C.

35. Cicerón, refiriéndose a la dura situación que supone el exilio y la desatención que provocará su marcha, advierte en ad Att., 53, 4, que Ático es un colaborador en las acciones llevadas a cabo por su esposa en el hogar, es decir, no actúa como tutor.

36. En ad Att., 57, 1 y 60, 6, comenta cómo, según las leyes Clodia de capite ciuis Romani y la directamente dirigida en contra del arpinate, lex Clodia de exsilio Ciceronis, no podía ser tratada la situación de Cicerón en el Senado, provocando también la duda acerca de la restitución de sus bienes incautados, por orden del tribuno de la plebe Clodio.

37. Ad fam., 7, 3; su esposa dispone de patrimonio suficiente para encargarse de la economía familiar -los gastos del hogar, el servicio, la educación y promoción social de sus hijos-, por tanto, en este pasaje se entiende que, como mujer casada sine manu, no debería utilizar sus bienes personales para la causa de Cicerón, el pago de sus deudas y otros gastos derivados de la situación, no es la forma habitual de contribuir con economía matrimonial. 
abundante patrimonio y el de su esposo, sino que años después, mientras Cicerón se encontraba como procónsul en Cilicia, tomó otra decisión que legalmente no correspondía a una mujer: gestionó el tercer matrimonio de su hija Tulia sin la intervención directa del padre o de aquel a quien confió la labor de consejero, su amigo Ático. ${ }^{38}$

Habiendo leído de qué modo lamenta Cicerón el desvanecimiento de la fortuna de su esposa, resulta prudente pensar que quizás Terencia se ocupara de todos aquellos asuntos para proteger así el factiblemente lóbrego futuro de sus hijos, consecuencia de las acciones de su padre:

[...] que a mi Marco, a quien, pobrecito, no dejo nada más que la ojeriza y la ignominia de mi nombre, lo protejas en todo lo que puedas; y que a Terencia, la más desgraciada de todas las mujeres, la apoyes con tus buenos oficios. ${ }^{39}$

Cicerón ofrece otro ejemplo de esta constante lucha por el patrimonio familiar, esta vez en una carta dirigida directamente a su esposa, cuyo contenido apoya la hipótesis de que el objetivo de Terencia bien podría ser proporcionar cierta estabilidad económica para Tulia y Marco en un contexto político frenético, al borde de otra guerra civil. Según la legalidad romana, Tulia quedaría bajo las enseñanzas de su madre en lo relativo a la vida matrimonial y cuidado del hogar, mientras que el padre habría de dirigir y financiar la carrera política del joven Marco. Sin embargo, ante las dificultades de Cicerón, el dinero emanará directamente del patrimonio de Terencia:

Me cuentas, Terencia mía, que tienes intención de vender unos inmuebles. ¡Pobre de míl Dime, te lo ruego, ¿cuál va a ser nuestro futuro? Y si nos continúa golpeando este mismo infortunio, ¿qué será de nuestro pobre niño? [...]. Solamente te digo que, si nuestros amigos cumplen con su deber, no nos faltará dinero. En caso contrario, no podrás conseguirlo con el tuyo. ${ }^{40}$

Puede incluso que esta fuese la razón del divorcio, tal vez Terencia se viera abatida por los gastos que afrontó intentando salvar a su marido, y aquella, viendo la excesiva inversión de su dote en asuntos concernientes a los errores políticos de su esposo, temía que sus hijos se vieran desamparados a causa de la caída en desgracia del padre. Quizás Ático aconsejó a Terencia que vendiera

38. Tulia se casó en tres ocasiones. La primera con Calpurnio Pisón Frugi, que murió en el 57 a. C., la segunda con Furio Crasipo en el 55 a. C. -según Suzzane Dixon, 1986, p. 118, n. 32- y, por último, con Publio Cornelio Dolabela.

39. Ad Att., 68, 5, Dirraquio, noviembre del 58 a. C.

40. Ad fam., 8, 5; de aquí deducimos que los inmuebles que pretende vender Terencia forman parte de su dote, por tanto, de su fortuna personal y no de la economía resultante del matrimonio. Terencia se encargaba, además, de conversar con los amigos de Cicerón e informarle de asuntos políticos en sus cartas; entre estos amigos que han de cumplir «con su deber» se encuentra Ático, quien estuvo prestando dinero a la familia durante años. 
algunas propiedades e incluso puede que le prestara dinero con tal fin.$^{41}$ Bajo estas condiciones, no resultaría extraño pensar que Terencia, acostumbrada, por las ausencias de su marido, a gestionar las finanzas familiares y a soportar las dificultades en soledad, tomara la decisión de casar a su hija sin el consentimiento último de Cicerón. En el año 51 a. C., mientras Cicerón permanece en Cilicia como procónsul, Terencia aprueba el tercer matrimonio de Tulia con un cesariano, el «encantador y degenerado» Dolabela (Pomeroy, 1999: 179). ${ }^{42}$ En una acción sin precedentes, madre e hija acuerdan que el último y definitivo candidato sea Dolabela. Aunque de la correspondencia con Ático se deduce cierta discusión entre el preferido del padre y los consejos que aporta el eterno amigo de la familia, sin embargo y de forma excepcional, la decisión última la toman las mujeres. ${ }^{43}$ En mi opinión, Terencia obró en consonancia con sus reflexiones, siendo consciente de que este nuevo acuerdo matrimonial era una estrategia para proteger a su familia. ${ }^{44}$

El distanciamiento entre Terencia y su marido comienza a ser notorio desde el 50 a. C., cuando Cicerón la responsabilizó de una desafortunada gestión en las cuentas familiares. Él cree que los bienes del patrimonio que Terencia vendió en cierta ocasión valían mucho más que el dinero que adquirió finalmente, o tal vez fuera cierto que Terencia habría mentido, obteniendo mayor beneficio y ocultándoselo a su esposo; desde ese momento será Ático quien se encargue de las finanzas de Cicerón:

En cuanto a lo que escribes sobre la dote [de Tulia para Dolabela], te ruego por todos los dioses que te encargues del asunto entero y protejas a la infeliz [Tulia] por mi culpa y mi descuido, con mis recursos, si hay alguno, y con tus propios fondos en la medida que no te cause inconveniente [...]. ¿En qué gastos se van los ingresos de mis propiedades? Hasta ahora nadie me ha dicho nunca que aquellos 60.000 sestercios que mencionas habían sido detraídos de la dote; jamás lo habría permitido. ${ }^{45}$

41. En diversas ocasiones Ático presta dinero a Cicerón y su familia, según se desprende de la correspondencia entre ambos (veáse nota 39), situación que proporciona a Ático una posición favorable para aconsejar e influir sobre el arpinate y sus decisiones, así como sobre Terencia y su gestión.

42. Cicerón era partidario de un joven arpinate (ad Att., 115, 10), aun así, su esposa y su hija decidieron, en contra incluso del consejo de Ático, que Dolabela sería el elegido; sobre Dolabela y sus encantos, veáse ad Att., 126, 12.

43. Con todo, según cuenta Valerio Máximo (4, 4, 10), en el año 214 a. C., Cneo Escipión quiso ser sustituido en Hispania para poder casar a su joven hija y proporcionarle una dote, a lo que el Senado respondió asumiendo «las obligaciones del padre; estableció una dote, según el parecer de la mujer y los allegados de Escipión, pagó la totalidad de la dote con el dinero del erario público y entregó a la joven en matrimonio». Por tanto, observamos cómo un siglo y medio atrás la esposa sí intervenía en asuntos concernientes al matrimonio de las hijas tales como la adjudicación y transferencia de la dote.

44. Ni Dixon (1986) ni Treggiari (2007) mencionan en sus trabajos la capacidad estratégica de Terencia en esta actuación. El matrimonio entre Dolabela y Tulia fue un acierto y también -aunque durante poco tiempo-un éxito político, conseguido por su madre.

45. Ad Att., 212, 2; ahora es Ático quien ha de encargarse de la gestión de la dote de Tulia, puesto que, como advertimos, ha desaparecido dinero y se ha retrasado el segundo pago -la dote solía fraccionarse en tres plazos-. Desde J. P. V. D. BALsdon, 1964 (ed. 1983), Roman Women. Their history and habits, Nueva York, p. 46, se da por supuesto que la duda sembrada en esta epístola acerca de un posible robo por parte de 


\section{CRISIS MATRIMONIAL Y DIVORCIO}

El tema principal de los trabajos contemporáneos acerca de la pareja que conformaban Cicerón y Terencia es el deterioro sentimental que, según los investigadores actuales, ${ }^{46}$ se percibe en la correspondencia. Éstos advierten una línea temporal en las cartas que emite a su esposa, donde se manifiesta un cambio que distribuyen en dos fases, una primera de amor y respeto, y otra que degenera en desconfianza y odio. Esta alteración en la correspondencia suele ser el razonamiento que comúnmente precede a las disertaciones acerca del divorcio. Asimismo, existe otro argumento según el cual la disminución cuantitativa de las cartas sería otro signo previo a la separación. A raíz de estos estudios, considero que quizás sea el momento de dar paso a nuevas formas para manejar esta información. ¿Cómo interpretar el distanciamiento comunicativo? ¿No es osado asumir aburrimiento en la pareja según el tamaño de la correspondencia? Aunque estos datos se conciben como reflejo de inestabilidad, conviene recordar que las cartas se intercambiaron en periodos de distancia física entre la pareja, por tanto entre una y otra pasaron incluso años. ${ }^{47}$

Teniendo en cuenta los estudios que siguen esta línea de investigación, a semejanza de los elaborados por Balsdon (1964), las dos profesionales que han trabajado de manera más profunda sobre la mujer de Cicerón han sido Dixon (1986) y Treggiari (2007). Sus interpretaciones han seguido caminos distintos -la primera a favor de la figura tradicionalmente vapuleada de Terencia, la otra en contra de este tópico plutarquiano-, no obstante ambas concluyen que la iniciativa del divorcio la tomó Cicerón y que fue la mala gestión económica lo que provocó la ruptura, a pesar de no haber motivos explícitamente declarados. $^{48}$

Terencia o de su liberto Filótimo, es el motivo de ruptura entre Cicerón y su esposa -dándose también por sabido que fue él y no Terencia, quien puso fin al matrimonio-.

46. Teresa Carp, 1986, pp. 343-56; Francesca Cenerini, La donna romana, Bologna, 2009, pp. 83-84; Rosario Cortés Tovar, «Espacios de poder de las mujeres en Roma», en Nieto IbÁÑEz, J. M. (coord.), XVIII Jornadas de Filología Clásica de Castilla y León. Estudios sobre la mujer en la cultura griega y latina, León, 2004, p. 203; Phyllis Culham, «Women in the Roman Republic», en Flower, H. I. (ed.), The Cambridge Companion to the Roman Republic, Princeton, 2004, p. 150; Suzanne Dixon, 1986; John K. Evans, 1991, p. 83; Elaine Fantham, Helene P. Foley, Natalie B. Kampen, Sarah B. Pomeroy, y H. A. Shapiro, Women in the Classical World, 1995, pp. 271-2; JANe F. GARDNER, 1991, pp. 89-91; EMILy A. Hemelrijk, 1999, p. 237, n. 63; Thomas Hillard, «Republican Politics, women and the evidence», Helios, vol. 16, 1989, pp. 174-175; WolfGANG SCHUller, Frauen in der römischen Geschichte, Konstanz, 1987, p. 49; SusAn Treggiari, 2007.

47. Conservamos 24 cartas de Cicerón a Terencia que corresponden al tiempo que pasó en el exilio (5857 a. C.), una de su estancia como procónsul en Cilicia (51-50 a. C.), otras de su ausencia durante la guerra civil (49 a. C.) y algunas del tiempo que pasó en Grecia hasta que volvió a Roma.

48. Plutarco, Cic., 41, da cuenta de los motivos que, según él, provocaron el divorcio, exponiendo que Terencia habría abandonado a su esposo, no visitándolo durante su estancia en Brundisio, y no auxiliando económicamente ni a él, ni a su hija, en dicha ausencia. No hay agentes ni fuentes directas que confirmen este argumento, que no obstante ha venido siendo aceptado por la investigación posterior sin ningún tipo de crítica. 
Sin embargo, lo único verdaderamente visible es cómo Cicerón se quejaba de la labor del liberto de su esposa, Filótimo, llegando a apodarle con terribles motes y encomendando a su amigo un cuidado constante: «[Ático] "vigila" si me aprecias "la petulancia del chapucero" $\gg .{ }^{49}$

Obviamente, no solo el exilio, que duró alrededor de un año y medio, entre 58 y 57 a. C., el proconsulado en Cilicia y su viaje a Brundisio en el 48 a. C., esperando el perdón de César, conducirán al distanciamiento, pero las razones definitivas no están claras. Ello es debido, en parte, al vacío que tenemos en la comunicación, correspondiente a los años en los que Terencia y Cicerón estaban juntos en un mismo lugar. En realidad, es peligroso acogerse a años de malestar matrimonial que culminaran en divorcio por los motivos anteriormente expuestos, ya que Cicerón encomendó la tarea del control de las finanzas a su esposa y de entre cientos de cartas enviadas a su familia y amigos solo en una desconfía de su labor.

Cicerón vuelve a Roma en el 49 a. C., momento en que da comienzo la guerra civil. En principio, se vivía una situación palpablemente tensa, pero los movimientos eran lentos y los aristócratas debían valorar las circunstancias antes de tomar partido definitivamente. Es por ello que no había motivo para huir de manera precipitada. Así pues, Terencia permaneció en la ciudad mientras Cicerón decidió quedarse en su casa de Formias, desde donde mantendrá de nuevo el contacto por correspondencia. Una vez más, Terencia hubo de ocuparse de las finanzas del hogar, dejando atrás la situación en la que Ático se hacía cargo de todo. En mi opinión, esta renovada confianza supone precisamente la normalidad de esta situación; es decir, que en ausencia del marido, la esposa se hacía cargo no solo del hogar, sino también de las finanzas concernientes a los demás elementos -tanto biológicos como materiales- que conforman la familia. Y es que una vez más, el problema era la falta de dinero, ahora con la amenaza tangible de una guerra próxima en el horizonte. Como de costumbre, durante la ausencia de Cicerón, Terencia y Ático se reunieron para acordar la utilización de tierras, propiedad de la mujer, como seguro de riesgo. Si había alguna complicación futura con los deudores, podían obtener dinero de las rentas o venderla definitivamente con tal fin. Cicerón decidió volver a abandonar la Urbs mientras César se aproximaba con su ejército. Al mismo tiempo, Terencia y Tulia cuidaron de su propia seguridad valiéndose de Dolabela como protector, ${ }^{50}$ quien como cesariano desempeñaría con mayor facilidad la responsabilidad. Por tanto,

49. Son numerosas las ocasiones en las que el liberto de Terencia es nombrado y acusado por Cicerón por temas económicos («el liberto de mi mujer» en ad Att. 118, 2 y 119, 1; «estúpido y tremendamente embustero», 200, 1; 211, 1; Filótimo haciendo «cosas delictivas», 227, 5; 233, 2; 234, 4; burlándose de su excesivo republicanismo en mayo del 45 a. C., 285, 3); en esta ocasión (ad Att. 123, 1 y 124, 1) juega además con la palabra griega philotimía, «petulancia», observación realizada por RodRíguez-PANTOJA, p. 351, n. 789, en la traducción que utilizo.

50. Ad Att., 135, 6; 136, 3. 
¿es justo seguir pensando que Terencia no sabía lo que hacía casando a su hija con este personaje, hombre manifiestamente cesariano?

[...] aconsejarte que te unieras a César y a nosotros [...] no puedo, ciertamente, inclinarme a ningún otro pensamiento salvo, naturalmente, el de darte el consejo evidente que no me permite callar mi sentido del deber como yerno. ${ }^{51}$

La ya habitual distancia entre la pareja, la incertidumbre acerca del futuro político de su esposo, además de los problemas reales por la falta de liquidez y la cercanía de una inevitable guerra civil, nos van acercando al final del matrimonio. En este contexto, Cicerón se encontraba en una situación personal muy peligrosa por haberse mostrado más pompeyano que cesariano. Por ello, con toda la información que tenemos ahora, resulta razonable plantear, al menos, que Terencia propusiera la separación, y que siendo mujer libre y disponiendo de los últimos retazos de su riqueza, podría dedicarse por entero a proporcionarles una estabilidad económica a sus hijos y a su pequeño nieto, el hijo de Tulia. Una estabilidad que las desavenencias políticas de Cicerón no le permitirían realizar, ya que corría el peligro de que sus bienes fueran confiscados junto a los de su esposo, en el caso de que este volviera a caer en desgracia. De este modo, lanzo la duda sobre Terencia terminando con el matrimonio: no le resultaría beneficioso estar casada con un «perdedor», un hombre venido a menos, indeciso, afectado por el exilio y profundamente dolido por lo que él consideraba ingratitud del pueblo al que había salvado de la locura de Catilina. Asimismo, casar a Tulia con un cesariano habría sido un mecanismo utilizado por Terencia de forma consciente, cuyo objetivo fue la reafirmación de nuevas alianzas políticas a favor de su familia, pero de forma que Cicerón no resultara perjudicado. En mi opinión esta boda fue uno de los últimos movimientos de Terencia para cortar los lazos que le unían a Cicerón. Posiblemente agotada, tras invertir mucho tiempo y gran parte de su propio patrimonio para ayudar a su esposo, y una vez resuelta la situación de Tulia, Terencia habría iniciado el proceso de divorcio.

A todos los agravios económicos de la familia de Cicerón, hemos de añadir la crisis que provocó el pago de la dote de Tulia en su unión con Dolabela. Sabemos que el arpinate se hallaba ausente cuando se concertó el matrimonio de su hija, para el cual Terencia acordó 60.000 sestercios sacados directamente del patrimonio del paterfamilias, es decir, del dinero de Cicerón sin que este lo autorizara expresamente. Asimismo, el divorcio entre Terencia y Cicerón en el 46 a. C. supuso que a este le fuese imposible restituir la dote de su esposa a la vez que pagar la dote de su hija al cesariano. Es importante advertir que ahora, faltando Terencia como respaldo económico y gestora de los bienes

51. Ad fam., 157, es una carta conservada de Dolabela a Cicerón donde claramente se observa la tendencia política del joven. En ella, Dolabela insta a su suegro a unirse al partido cesariano, estrategia que forma parte del intento de César de ganarse a los optimates aprovechando la relación familiar que une a estos varones. 
familiares, Ático habrá de auxiliar a su amigo en asuntos financieros para el pago de la dote de Tulia, además de convenir las cláusulas de la separación. Tulia, la queridísima hija de Terencia y Cicerón, ${ }^{52}$ falleció en el año 45 a. C. y, sorprendentemente -a pesar del corte sociológico que siguen estudios como el de Treggiari (2007)-, la investigación siempre ha ido encaminada al declive emocional que sufrió el padre; nadie ha considerado el dolor que debió sufrir su madre, de la que nunca se separó mientras vivía..$^{53}$ Desde este momento, Terencia es envuelta en una enorme nube negra y desaparece. Evidentemente, la causa es la falta de fuentes. Cierto es que solo puede ayudarnos aquí la obra epistolar de Cicerón, pero no debemos incurrir en la constante de aducir al hecho de que, tras su divorcio, nunca más volvieran a escribirse, ${ }^{54}$ ya que la mayor carencia de información para reconstruir la vida de nuestra protagonista sigue siendo la falta de la correspondencia enviada por Terencia. Cicerón fue asesinado en el año 43 a. C. sin reponer lo que le debía a su mujer concerniente a la dote, patrimonio que, como expliqué al principio de este trabajo, es exclusivo de la esposa y ha de ser restituido: «...a mí me preocupa mi patrimonio. ¿«Mi patrimonio» digo?; más bien mi reputación, pues aunque es tanto lo que se me debe, no me queda ni para pagar a Terencia». ${ }^{55}$

Para terminar, me animo a contestar ahora la pregunta que planteaba al comienzo de esta disertación: quién fue Terencia. Además de que fue la primera esposa de Cicerón, lo único que sabemos con certeza es que Terencia fue una mujer adinerada, cuyo poder se vio limitado por lo que unos estudiosos denominarían tradición romana y otros, simplemente, legalidad. Las leyes podían ser esquivadas en ocasiones si venían acompañadas de un contexto favorable, llegando hasta nosotros en forma de anécdotas protagonizadas por personajes excepcionales. Al final de la República, mujeres como Servilia, madre de Bruto, Fulvia -esposa de dos de los hombres políticamente más «exaltados» de los últimos tiempos- o Livia -la primera mujer en detentar el poder individual-, destacaron por invadir un espacio masculino como fue el político. En este sentido, Terencia no solo actuó en esta esfera, sino que, además, adquirió esa independencia gracias al aprendizaje obtenido por medio del control de las finanzas, llevado a cabo durante las múltiples ausencias de su esposo.

52. Acerca de la profunda devoción que sentía Cicerón por su hija, Tulia, consúltese Judith P. HALLETT, Fathers and daughters in Roman society: women and the elite family, Princeton, 1984, pp. 133 y ss.

53. Como único sujeto comunicador de este acontecimiento tenemos a Cicerón. En ad Att., 254, 1, se aprecia el dolor del que es protagonista a través de la idea de construir un sacrarium en memoria de Tulia que, finalmente, no se realizará-. La falta del testimonio de Terencia es, una vez más, el motivo de la evasión de sus propios sentimientos en los estudios.

54. Las últimas cartas a Ático demuestran preocupación por Terencia, más bien por el testamento que firmó a favor de sus hijos.

55. Esta es (ad Att., 426, 5) la última carta que hay escrita sobre Terencia, redactada en noviembre del 44 a. C., debiéndosele todavía a la mujer un plazo en restitución de la dote. 


\section{CONCLUSIONES}

Del mismo modo que sucede la primera vez que vemos una clásica y popular pieza teatral, a pesar de que en conjunto permanece aparentemente intacta, son «nuestros ojos» los que juzgarán finalmente tal composición. Esta obra de teatro ha permanecido estática e inalterable al paso del tiempo, hasta convertirse en un organismo inmortal. Por el contrario, lo verdaderamente mutable es cómo percibimos, tomamos y, posteriormente, trabajamos esa «lluvia» inesperada de imágenes hasta que logramos acomodarlas en nuestra mente a placer: nosotros somos los jueces y el resultado no es más que la sensación personal de un elemento inerte. Precisamente esto es lo que pasa con las fuentes literarias antiguas y «los ojos» con que fueron, son y serán analizadas. De igual modo, la investigación en torno a la que fue compañera de Cicerón también es fruto de esta subjetividad propia de las personas y del contexto social en el que se encuentran. Es por ello que el estudio histórico en general siempre estará vinculado a los cambios en el medio de aquellos que afrontamos esta labor.

En efecto, todo lo que conocemos acerca de la vida de Terencia nos ha llegado a través de la obra epistolar del que fue su esposo, Cicerón; por tanto, esta es nuestra única fuente. Nuestros ojos -y los de autores como Plutarcojuzgaron a esta mujer en consonancia con la doctrina e ideas de su tiempo y su entorno. Lo mismo sucede con los ya mencionados trabajos de Dixon y Treggiari. Es así como descubrimos aquello que no reflejan las cartas: cuándo nació, bajo qué condiciones se produjo el matrimonio, cuáles eran sus actividades cotidianas, cuál fue el verdadero motivo de su divorcio y por qué no se llevó a cabo con anterioridad, si sentían verdadero amor el uno por el otro o si las fórmulas afectivas que observamos en la correspondencia eran fruto de la técnica literaria de Cicerón, qué relación mantuvo con sus hijos o, también, cuál era el contenido de las cartas que escribió la propia Terencia. Naturalmente, son aspectos de esta célebre mujer que se nos escapan y nunca podrán ser recuperados. La vida, al fin y al cabo, implica una voluntad personal, una actuación, un pensamiento; atributos que los historiadores no podemos desentrañar ni establecer fácilmente.

A pesar de los inconvenientes, combinando la información que hemos recogido, la palabra de Cicerón y las compilaciones de derecho romano imperial -posteriores a los acontecimientos aquí narrados-, podemos aventurarnos a formular excepcionales hipótesis. De este modo, esto es lo que sí sabemos sobre Terencia: gozó de una gran responsabilidad llevando no solo la contabilidad del hogar con la ayuda de un liberto, Filótimo, como era costumbre a finales de la República, sino que también hubo de ocuparse de las finanzas correspondientes a su ausente esposo. La confianza que se desprende de la obra epistolar de Cicerón hace que vislumbremos incluso la capacidad política de esta mujer a través de comentarios sobre la situación en Roma, 
agradecimientos sobre el contacto que mantiene la mujer con los varones que pueden ayudarle a volver, pero no solo durante el exilio, sino también durante el ejercicio de la magistratura proconsular en Cilicia. Actúa como materfamilias «privada», pero también "pública», forzada por el distanciamiento de la pareja a sustituir a Cicerón y la pérdida del rol como paterfamilias. He ahí la peculiaridad de Terencia, una mujer comprometida con las cuestiones de su esposo, interviniendo incluso en política, cuya extraordinaria gestión financiera tanto en su espacio como en el espacio correspondiente al varón, la han convertido en una figura histórica especialmente interesante hasta nuestros días.

La «excesiva» responsabilidad que Cicerón deposita sobre Terencia en lo referente al control de las finanzas, es vista por la mayoría de investigadores como algo peculiar. No obstante, yo interpreto que esta competencia económica bien podría responder a la forma natural de actuación entre las mujeres de la elite de esa época. Lo que quiero decir es que no es un acontecimiento especial, sino una práctica habitual republicana; fíjense sino en Cornelia, madre de los hermanos Graco, tan venerada por la literatura posterior como ejemplo de virtud femenina. Su condición de viuda y, por tanto, rol predominante dentro y fuera del hogar, le permitió actuar asimismo como gestora. Su educación era tal y su riqueza tan grande que no necesitó casarse de nuevo. ${ }^{56}$

En un tiempo en el que las mujeres eran visiblemente más libres que en siglos anteriores, Terencia es un precedente, no solo en el control de las finanzas -lo cual he sugerido que podría interpretarse como algo habitual-, sino en cómo gestionó dicho control económico, reservando su fortuna para su familia y la protección del estatus personal que les acompañaba. Lo auténticamente revelador es que en ningún caso realizó dicha labor consultando con su marido. Terencia sienta un precedente porque rescata verdaderamente a su familia, la salva de la destrucción, y en último término, hace uso de sus conocimientos políticos a través de la elección del tercer esposo de Tulia. No sabemos si la hija tomó la decisión con su madre, lo que sí sabemos es que Cicerón no aprobaba el matrimonio y ni siquiera Ático pudo evitar el compromiso. Si fue decisión suya o pidió consejo a otras personas lo desconocemos. Pero la confianza que Cicerón depositó en su esposa, convirtiéndola en informadora y consejera de lo que acontecía en la vida pública durante sus ausencias, ${ }^{57}$ pudo servir a Terencia para introducirse en el juego político. Con esta experiencia, fue capaz de organizar el matrimonio de su hija con un cesariano, una unión que resultó ser la mejor opción para el futuro no solo de Tulia, sino también el de su familia.

56. En contraposición a la enérgica crítica que sobre Terencia realiza Plutarco, el mismo autor se deshace en elogios cuando se refiere a Cornelia, destacando la educación que dio a sus hijos y la buena gestión que realizó desde la viudedad (Tib., 1). Puede consultarse su biografía de la mano de Suzzane Dixon, Cornelia. Mother of the Gracchi, Londres, 2007.

57. Emily A. Hemelrijk, p. 189. 
Volviendo a la cuestión de si Terencia pudo haberse planteado el divorcio durante el exilio de Cicerón, hemos de tener en cuenta que quizás le hubiese sido difícil encontrar otro esposo políticamente comprometido y próspero para seguir aumentando su fortuna y ayudar a sus hijos con ello. No obstante, la mejor vía de elevación política era a través de sus hijos, asegurándoles, en su papel de materfamilias, un futuro seguro en tiempos tan convulsos como el final de la República. En mi opinión, fue después cuando Terencia tomó la decisión. Efectivamente, en la correspondencia se aprecia el distanciamiento de la pareja, pero posteriormente, en las cartas a Ático, se observa cierto interés sobre la exesposa en relación a la restitución de la dote. Tradicionalmente se interpreta que fue Cicerón el que terminó con el matrimonio, pero llegados a este punto hemos de recordar que solo conservamos la correspondencia que él mantuvo con sus allegados y no la de estos, así que Terencia -aunque guardó las cartas de su marido, tal vez porque le transmitió en algún momento su intención de publicarlas- es, tristemente, un sujeto mudo para nosotros.

Con el fin de reagrupar los temas tratados en este trabajo, compendiaré un esquema. En primer lugar, hemos visto cómo, según las leyes romanas, una mujer casada -incluso de la condición de Terencia- tenía restringidas ciertas acciones, siempre bajo la supervisión del esposo o tutor y cuya respuesta masculina se vio reflejada en el mantenimiento de leyes tales como la lex Voconia, en claro detrimento de la ostentación económica de la mujer. En segundo lugar, analizando la obra epistolar de Cicerón hallamos que su esposa hace más de lo que estaría legalmente establecido, creándonos la insoluble duda -al menos no con fuentes directas- de si esta era una excepción o una práctica habitual entre las mujeres de su clase. Por último, sopesamos la carencia de información de una y otra fuente para aportar nuevos datos, siguiendo aquellos trabajos que hacen uso de la metodología utilizada para la historia social. Sin embargo, también esto nos plantea dudas sobre la actuación de Terencia, ya que a través de sus competencias en el ámbito familiar, podría haber actuado en dos ocasiones de forma anómala desde el punto de vista legal; la primera ocupándose del matrimonio de su hija y Dolabela, y la segunda poniendo fin a su propio matrimonio. Aunando la legalidad, la obra del arpinate y las técnicas sociológicas, podríamos comenzar a disipar algunas dudas. Apoyándonos en el testimonio de Cicerón acerca de la inoperancia de la anacrónica ley Voconia de 169 a. C. (de rep., 3, 17), aún sufrida por las mujeres de su tiempo, advertimos la distancia que existe entre las leyes y su cumplimiento en la vida cotidiana.

Del mismo modo que Cicerón creó de Clodio «una imagen distorsionada (...) usando un lenguaje (...) aceptado sin crítica por la historiografía moderna», ${ }^{58}$ me gustaría hacer lo propio con el personaje de Terencia. Ciertamente, Cicerón representa una guía para los especialistas del periodo tardorrepublicano, la base y el modelo gracias al cual conocemos el desarro-

58. Cita textual en Francisco Pina Polo, «Cicerón contra Clodio: el lenguaje de la invectiva», Gerión, Madrid, 1991, p. 131. 
llo político y las transformaciones propias de estos momentos, pero debido a la gran cantidad y variedad del material que conservamos gracias a él, no solemos ser críticos con este autor, aceptando a pies juntillas lo que transmitió. Según este paradigma, el comportamiento de la mujer de Cicerón debería corresponderse con el patrón de mujer aristócrata de finales de la República que aquel describe en sus escritos. Lejos de esto, y aunque nuestra protagonista suscita más incógnitas que soluciones da, habríamos de resolver que Terencia fue realmente una mujer excepcional. Siendo críticos, la diligencia con que manejó las finanzas familiares -de las que se ocupó más allá de lo que le correspondería-, representa la pugna entre la matrona a la que nos referíamos al principio y la mujer tardorrepublicana.

Con todo, es una lástima que, del mismo modo que sucede con Salustio y la conspiración de Catilina -ya que presenta un discurso alternativo al de Cicerón, enriqueciendo los estudios-, no exista un enfoque coetáneo y distinto al del arpinate sobre la actuación de Terencia. Obviamente, es un hecho que representa una gran merma para la investigación. No obstante, dejo muestra de cómo «los ojos que juzgan» hacen que la información, lejos de quedar imperturbable, se renueve constantemente. Como aquella obra de teatro. 